\title{
An ICT Based Solution for Pesticides Authenticity Verification: A Case of Tanzania
}

\author{
Catherine Cleophace Ngirwa ${ }^{1 *}$, Mussa Ally ${ }^{1}$ \\ ${ }^{1}$ Nelson Mandela African Institution of Science and Technology (NM-AIST), Arusha, TANZANIA
}

*Corresponding Author: ngirwac@nm-aist.ac.tz

Citation: Ngirwa, C. C. and Ally, M. (2018). An ICT Based Solution for Pesticides Authenticity Verification: A Case of Tanzania. Journal of Information Systems Engineering \& Management, 3(4), 27. https://doi.org/10.20897/jisem/3938

Published: November 10, 2018

\begin{abstract}
Pesticides authenticity is important for human health and environmental protection also economic progress of users, dealers and the government benefits through levies. In order to ensure that authentic pesticides are sold in Tanzania, laws have been enacted and government bodies given mandate to enforce these laws. Despite the efforts, counterfeits are found in markets. Companies that spend a lot in research so as to produce authentic pesticides products end up losing hope as no substantial return in investment. This study targets on an ICT based solution for pesticides authenticity verification in the market which is a case study of Arusha region. In order to prove the need for the solution, literature review has been done and presentation of data gathered from the identified three groups of pesticides stakeholders, which are regulatory authority, registrants/formulators/importers and users preferably farmers all from Arusha region. The findings from the collected data reveals that, despite high awareness on availability of counterfeit pesticides among respondents, still most of them declared to have been buying counterfeits. Hence, there is a need of more reliable ICT based solution to help pesticides users in authenticity verification of products during purchase.
\end{abstract}

Keywords: ICT, pesticides, authentic pesticides, counterfeit pesticides, ODK

\section{INTRODUCTION}

Information and Communication Technology (ICT), plays a great role in human life, as it has been a catalyst of information management in different sectors. It is also been used as a tool for providing education opportunities to underserved who are geographically dispersed through teleconferencing technologies and increased students' performance by facilitating teaching and learning (Tinio, 2002; Vitanova et al., 2015). In business, through ecommerce ICT has been able to cater many customers in shorter time and in effective manner while increasing competitive edge of a particular business (Carnoy, 2005). ICT has correspondingly been identified to improve the quality and efficiency of healthcare systems and workers and facilitate information and knowledge flow of agriculture in rural areas (Idowu et al., 2003; Lwoga et al., 2010).

"Pesticides are chemical substances used to kill, repel or control certain forms of plants or animal lives that are considered to be pests" (U.S. (NIEHS), 2016). They have varieties of applications based on the user intentions. Roughly 85 percent of pesticides currently used in the world are devoted to agricultural sector, and the remaining percent for sanitary measures (Yáñez et al., 2002).

Product authenticity refers to; originality, quality commitment and credibility, heritage and style persistence, scarceness, sacredness and purity (Liao and Ma, 2009). As this study is concerned, pesticides authenticity would 
refer to quality commitment and credibility of the pesticides products. In ensuring that authentic pesticides products are sold in Tanzanian market, laws have been enacted and government bodies given mandate to enforce them. Among the regulations that govern commercial distribution of pesticides are; the Pesticides Control Regulations Act No.18 of 1979 section 41(8), which states that "Every person who for commercial purposes or disposal in any way for use by the public imports, manufactures, formulates or compound any pesticide shall register that pesticide in accordance with the Act and these Regulations" (Tropical Pesticides Research Institute, 1984). Despite these regulations, Lahr described information published by AGENDA for Environment and Responsible Development reported that, about 40 percent of pesticides sold in 2012 in Tanzania, were substandard (Lahr et al., 2016). The work of (Singh et al., 2015), described substandard (counterfeit) pesticides are those which are not registered, having low/incorrect active ingredients, trademark infringed or sometimes misbranded. Going further Singh, Smita and Panchal, described that among the identified reasons of using these substandard pesticides in India, is lack of awareness and not being able to differentiate genuine from non-genuine pesticides.

The magnitude of counterfeits pesticides is great also worldwide. Europe pesticide business estimated to lose about $\$ 260$-\$370 million U.S. dollars, also counterfeit pesticides in China and India believed to comprise about 3020 percent of the whole pesticides in the market respectively (Fishel, 2009). Additionally, Fishel discusses the problems caused by counterfeit pesticides which includes; problems to the health of customers and farmers, harm to the environment and economic damage to people and governments. From literature review, the need of a reliable ICT based solution for authenticity verification of pesticides has been revealed.

Additional to the literature review, this paper presents results from data collection which involved three categories of pesticides stakeholders in Arusha Tanzania; pesticides regulatory authority, pesticides registrants/formulators/importers and pesticides users preferably farmers. From the regulatory authority, this study aimed at understanding their functions and responsibilities in regard to pesticides management, quality control and how often it is done also the procedures, regular sharing of information with registrants/formulators/importers, if there is any electronic system for management of pesticides products and dealers, inspection process and challenges facing during the inspection. Similarly from the pesticides registrants/formulators/importers aimed at understanding their means of storing and sharing information about the products, status on counterfeited of their products, actions which have been taken so far in combating counterfeits, also their views in the use of ICT based solution for pesticides authenticity verification. From pesticides user's questionnaires were used to collect information on awareness and status of counterfeits pesticides, means which they use in reporting problem arise when products don't work as expected. On the other hand, their views on efficiency of the authenticity methods and their view on ICT based solution for pesticides authenticity verification.

The organization of this paper is as follows; section one presents brief introduction of the study and the stakeholders. Section two presents background information on similar studies done in developing countries. Section three describes methodology used in gathering the needed information from various identified groups of stakeholders. Section four is the results from gathered information. Section five describes the proposed solution. Section six is conclusion.

\section{BACKGROUND}

On the other hand, different ICT approaches and methods have been suggested in developing countries and others even implemented towards combating counterfeits. The suggested methods for product authentication includes the cloud technology, mobile and syndication technologies, rapid alert systems, coded stickers, website seals and cyber warning and all of these can be a success by conducting authentication and verification related activities, which involves; organizations and stakeholders collaborations as well as public awareness campaigns (Isah, 2012).

The following are ICT efforts which have been done by different stakeholders in combating counterfeit pesticides in various developing countries which includes Greece, Taiwan, Kenya, Uganda and Tanzania.

Starting with the Microsoft Access managed database proposed in Greece (Vassiliadou et al., 2011). It provides information on the recommended and genuine pesticides and information on how to use them. It facilitates communication between the regulatory authority and potential users and dealers of the pesticides.

Also the regulatory information system was proposed in Taiwan (Fei, 2014). The system covers the registration, quality regulation also establishment and evaluation of maximum residue limits and field monitoring of pesticide residues. It also, provides information to users of the services concerning how to use pesticides products.

On the other hand there is a Short Message Service (SMS) system for pesticides products authenticity verification in Kenya (Syngenta, 2011). The Kenya Plant Health Inspectorate has established this simple SMS 


\section{Data Collection Sites}

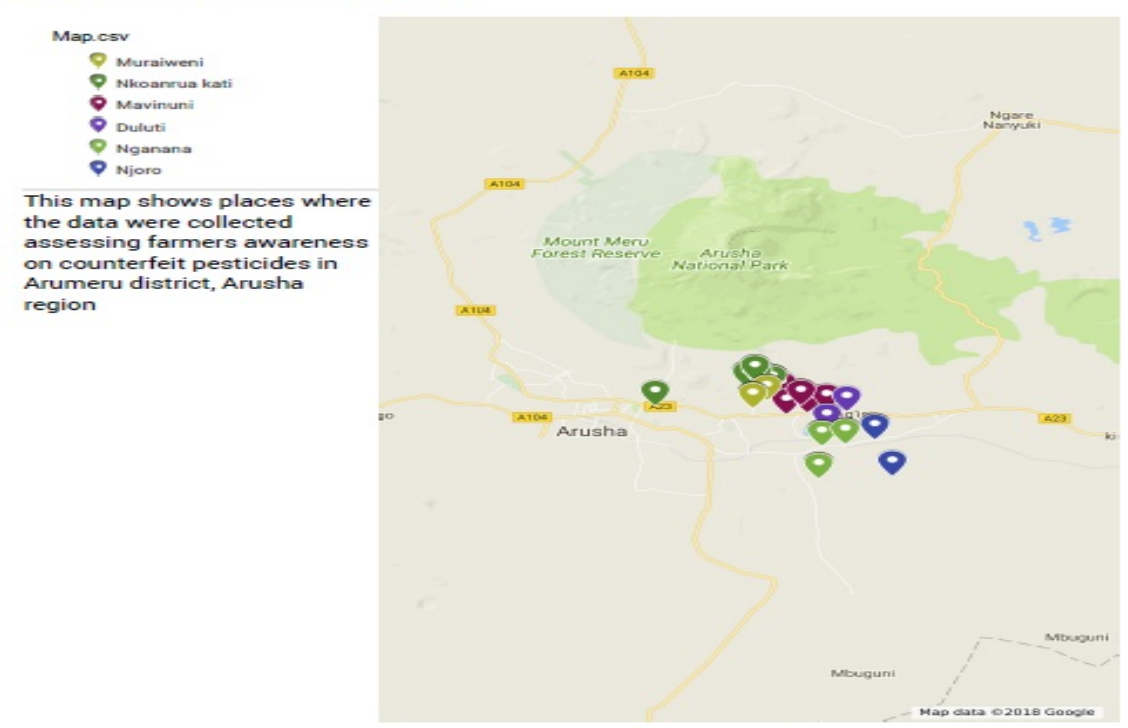

Figure 1. Data Collection Sites

system that allows farmers to check the authenticity of agro inputs - seeds, fertilizer, chemicals by sending text that contains dealer's license number and gets an SMS confirming the status of the product.

Similarly in Uganda, the electronic pesticides authenticity verification system uses SMS was implemented (Ashour et al., 2015). It provides access for user to send the authentication code found after scratch off the product label and receives back an SMS confirming the authenticity of the product. Only products with valid scratch code, considered authentic.

In Tanzania, an ICT model to combat counterfeits agro-inputs was proposed (Shao and Edward, 2014). The proposed model requires communication between the regulatory authority and the manufacturers on agreed code to be kept on the products then update the database server for customer to authenticate during purchase through SMS. Similarly to the one in Uganda, only products with valid scratch code, considered authentic.

\section{METHODOLOGY}

This section presents the methods used in collecting the needed information from pesticides stakeholders, description of the study area, sample size and sampling technique used. Implementation methods and design decisions of the proposed solution is out of the coverage of this paper.

\section{Methods}

Mixed methods to data collection were used, which is a combination of qualitative and quantitative methods of data collection similarly the results should be analyzed both qualitatively and quantitatively (Tashakkori and Teddle, 1998; Tashakkori and Teddlie, 2010). From qualitative methods, interviews were used and for quantitative methods, questionnaires were used to gather the needed information from the pesticides stakeholders. Different groups of pesticides stakeholders were identified including the targeted information from each group as described in section one. The involved pesticides stakeholders in this study includes; pesticides regulatory authority in Tanzania, pesticides registrants/formulators/importers and pesticides users preferably farmers. This is due to the fact that there has been a spectacular increase in need and importation of agricultural pesticides (Lahr et al., 2016; Ngowi, 2002).

\section{Description of the Study Area}

This is a case study of Arusha region located at $3.3869^{\circ} \mathrm{S}, 36.6830^{\circ} \mathrm{E}$ coordinates. The whole process of data collection took place from January to March, 2018. The study involved three groups of pesticides stakeholders, which are pesticides regulatory authority, pesticides registrants/formulators/importers and pesticides users preferably farmers. Staffs from pesticides regulatory authority were involved in interviews. Staffs from randomly selected six companies which fall in category of pesticides registrants/formulators/importers involved in interviews as well. Random selection was chosen as way to give all companies equal chance to participate in the study (Denscombe, 2014; Meng, 2013). The study also involved farmers with pesticides buying experiences from six hamlets (see Figure 1); Mariweni, Nkoanrua kati, Mavinuni, Duluti, Nganana and Njoro which are in wards of Akheri, Kikwe and Nkoanrua in answering prepared questionnaires. 


\section{Sample Size and Sampling Techniques}

Staffs from pesticides regulatory authority and the six randomly selected companies were interviewed based on availability. Likewise, a total of 170 farmers from Arumeru district, which comprise a total of 49,292 households that are involved in agriculture, it is also the leading district in pesticides use were involved (The United Republic of Tanzania, 2012). Questionnaires prepared in Open Data Kit (ODK), since it is a mobile, faster and reliable means of collecting needed information from target audience (Hartung et al., 2010). Findings from interviews were prepared and the analysis for questionnaires were done using excel.

\section{FINDINGS FROM DATA COLLECTION}

\section{Pesticides Regulatory Authority}

Their responsibilities in regard to pesticides management is concerned with registration of pesticides products and registrants/formulators/importers, issuing of pesticides importation permit, regular quality control of pesticides products which are imported or formulated to be used in the country. Also the authority is responsible for inspection of the products once in the market, making sure that they are registered and of the expected quality. Nevertheless it is responsible for inspection on regulations abidance by the registrants/formulators/importers and the retail sellers of pesticides. Basically, the regulatory authority identifies products by batch numbers. This is due to the fact that, in case the particular product has been identified and/or to not being working as expected then all of the products in that batch has to be written off from the market.

Despite, the efforts and procedures to ensure that the products are of the expected quality, still during inspection processes which are conducted by the regulatory authority's inspectors, products which are not registered, sometimes trademark infringed or those registered but that particular batch does not have the required permits are found in the market.

Among the initiatives done by the regulatory authority so as to reduce counterfeits in the market includes educating and issuing certificates to shops sellers which started in early 2005 [on how to read and understand products labels so they could identify counterfeits]. The knowledge has been of help in reducing counterfeits but still there are sellers who haven't been complied. Who takes advantage that pesticides users don't have the knowledge that (sellers) have and sell counterfeits.

Midst the identified challenges faced by the inspection team is the scarcity of resources especially money to reach more areas. Inspection handling issues are done on paper based, which makes difficulties in organization of the required information at real time.

\section{Pesticides Registrants/Formulators/Importers}

These are the registered agents for importing, formulating or even distributing particular pesticides products in Tanzania. Interviews conducted with six random selected companies. The findings were that 4 among 6 interviewed companies didn't have any electronic system to store basic information about the products either manufacturing and/or importations. Nevertheless, even those having electronic systems still the exchange of information with the pesticides regulatory authority is conducted on paper based. These companies declared to have been receiving reports of counterfeits from their sales representatives around regions and have been reporting to authorities about the problems without any follow-up or promising response. Respondents seconded the idea of an ICT based solution for pesticides authenticity verification, quote from one of the respondents "That idea shall work, just make sure that the displaying information to the users are more detailed for user to be able of distinguishing counterfeited from genuine"

\section{Pesticides Users}

The following are the findings analyzed from 170 questionnaires in Arumeru district. Where the information presented in Table 1, includes; pesticides users' awareness on counterfeits, sources of information on counterfeits, status on whether respondents have been victims of counterfeits or not, reporting complaints for products which haven't worked as expected, pesticides verification methods in use, rating of the pesticides verification methods in use and pesticides user's views on ICT based solution for products authentication.

\section{From Table 1}

There is high awareness in availability of counterfeits pesticides among respondents, where $85.88 \%$ are aware.

Furthermore it was of interest knowing the sources of information for which the respondents who declared to be aware of availability of counterfeits heard the information. Respondents were allowed to choose more than one source of information. The results shows that despite radio, television, newspapers and social media being among the sources which people have heard of counterfeits, $61.18 \%$ of all respondents identified other sources as one of 
Table 1. Presents Analyzed Results from Questionnaires

\begin{tabular}{|c|c|c|c|}
\hline REQUIREMENT & TYPE OF RESPONSES & NUMBER OF RESPONSES (n) & PERCENTAGE (\%) \\
\hline \multirow[t]{3}{*}{ 1. Awareness of counterfeit pesticides } & Yes & 146 & $85.88 \%$ \\
\hline & No & 24 & $14.12 \%$ \\
\hline & Total & 170 & $100 \%$ \\
\hline \multirow[t]{6}{*}{ 2. Sources of information on counterfeits } & Television & 33 & $19.41 \%$ \\
\hline & Radio & 95 & $55.88 \%$ \\
\hline & Newspaper & 31 & $18.24 \%$ \\
\hline & Social Media & 9 & $5.26 \%$ \\
\hline & Other Sources & 109 & $61.18 \%$ \\
\hline & $\begin{array}{l}\text { Total (multiple selection } \\
\text { for } 146 \text { respondents) }\end{array}$ & & \\
\hline \multirow[t]{4}{*}{ 3. Bought counterfeits } & Yes & 116 & $79.45 \%$ \\
\hline & No & 28 & $19.18 \%$ \\
\hline & Don't Know & 2 & $1.37 \%$ \\
\hline & Total & 146 & $100 \%$ \\
\hline \multirow{3}{*}{$\begin{array}{l}\text { 4. Reporting complaints for products } \\
\text { which didn't perform as expected }\end{array}$} & Yes & 31 & $26.72 \%$ \\
\hline & $\overline{\mathrm{No}}$ & 85 & $73.28 \%$ \\
\hline & Total & 116 & $100 \%$ \\
\hline \multirow[t]{5}{*}{ 5. Pesticides verification methods in use } & Brand & 106 & $62.35 \%$ \\
\hline & Expiry date & 154 & $90.59 \%$ \\
\hline & Type ingredients & 78 & $45.88 \%$ \\
\hline & Nothing & 6 & $3.53 \%$ \\
\hline & $\begin{array}{l}\text { Total (multiple selection } \\
\text { for } 170 \text { respondents) }\end{array}$ & & \\
\hline \multirow{6}{*}{$\begin{array}{l}\text { 6. Rating of the pesticides verification } \\
\text { methods in use }\end{array}$} & Very effective & 1 & $0.59 \%$ \\
\hline & Capable and effective & 60 & $35.29 \%$ \\
\hline & Somewhat effective & 60 & $35.29 \%$ \\
\hline & Needs development & 43 & $25.29 \%$ \\
\hline & Unsatisfactory & 6 & $3.54 \%$ \\
\hline & Total & 170 & $100 \%$ \\
\hline \multirow[t]{5}{*}{ 7. Views on ICT based solution } & Strongly agree & 39 & $22.94 \%$ \\
\hline & Agree & 91 & $53.53 \%$ \\
\hline & Neutral & 16 & $9.41 \%$ \\
\hline & Disagree & 24 & $14.12 \%$ \\
\hline & Total & 170 & $100 \%$ \\
\hline
\end{tabular}

the most chosen among five sources of information they heard of counterfeits. These other sources were mentioned as, hearing from fellows and/or personal experience in using counterfeit pesticides.

Besides, the table presents the percentage of respondents in regard to status of been or not buying counterfeit pesticides for the respondents who declared to be aware of counterfeits availability. From the results, $79.45 \%$ of respondents have bought counterfeit pesticides and the rest not.

Going further checking whether there were any efforts of reporting the incidents for those respondents who claimed to have been bought counterfeits, it show that $73.28 \%$ of the respondents who bought counterfeit pesticides didn't report the incidents. Among the mentioned reasons of not reporting is, not knowing the proper channel to follow in reporting the incidents. For those reported to the shops where they bought the products claimed that sellers blamed them (users) not to properly follow the usage and storage instructions as per product descriptions.

It felt similarly of important to understand current practice of users in authenticating pesticides products during purchase, also users were allowed to select more than one method. Where $91 \%$ of all respondent selected expiry date as one of the four most used authenticity verification method, followed by those checking brand, type ingredients and those who checks nothing just trusts the pesticides sellers on what is the best product to use for their needs. Respondents' ratings of the effectiveness of methods which are in use for authenticity verification of pesticides products were collected, where more than $60 \%$ were not satisfied by the methods currently in use.

As this research targets on ICT based solution for pesticides authenticity verification during purchase, respondents opinions were collected concerning the matter. From the responses, more than $70 \%$ of the respondents seconded the idea.

\section{PROPOSED SOLUTION}

From the data collection it is clear that most of pesticides users are aware of availability of counterfeits from different sources, despite high awareness they still declared to fall into buying counterfeits and they don't have a clear channel to report their misfortune. Hence, this research study targets on development of a mobile application 

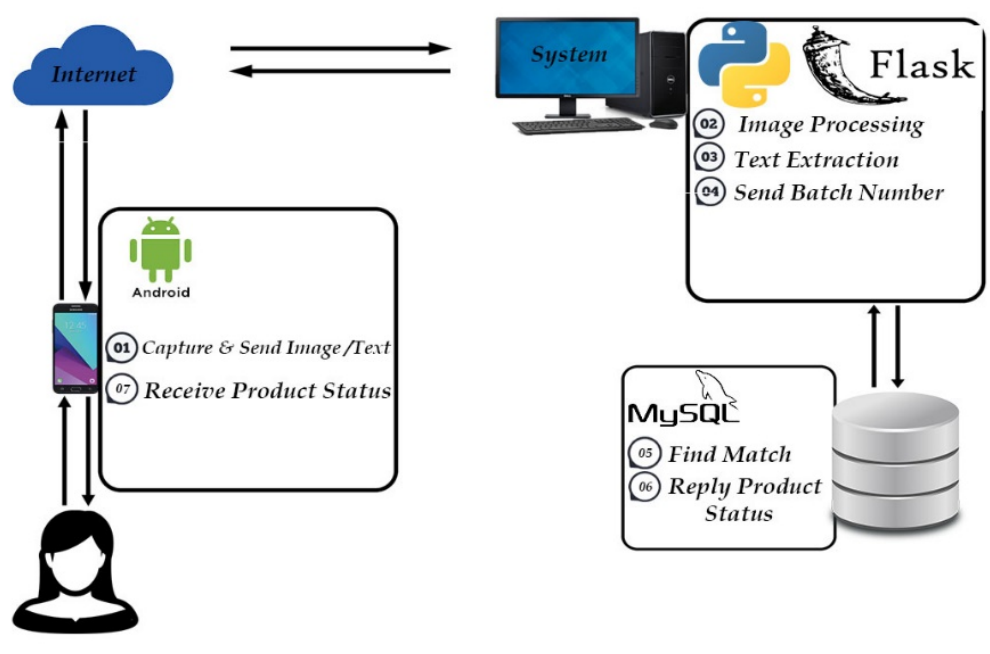

Figure 2. Research Framework

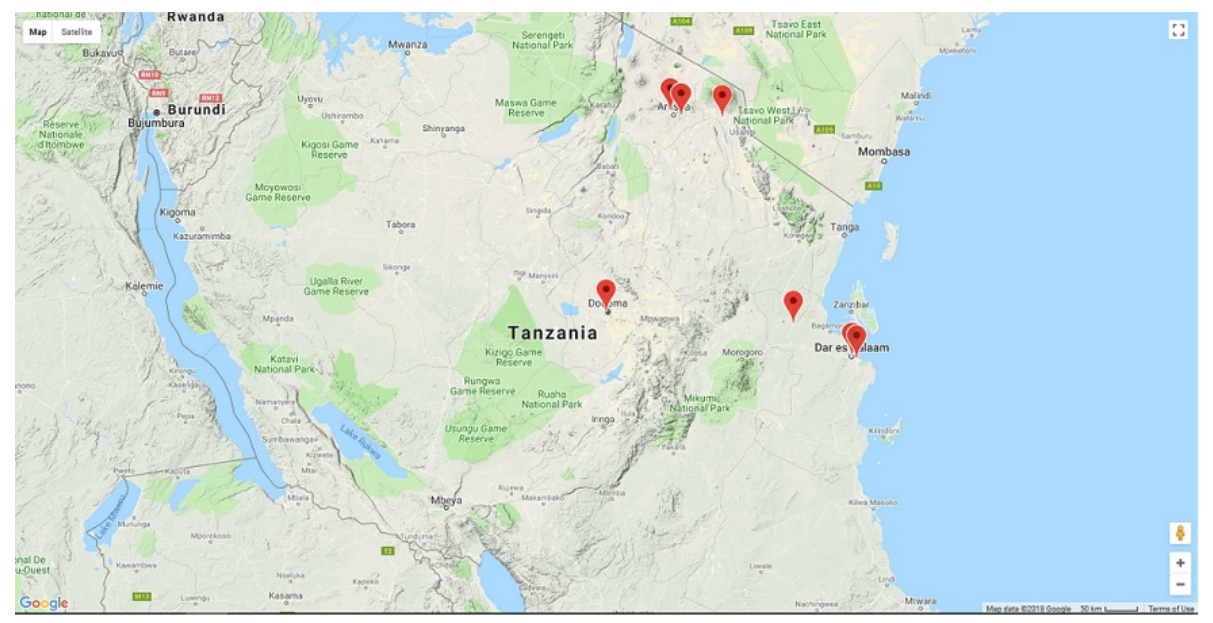

Figure 3. Map for Locating Counterfeits

that shall provide the service of pesticides products authenticity verification also reporting problems/complaints for products which haven't worked as expected.

The choice of a mobile application is due to the development of telecommunications market in Africa, where 60 percent of the population has mobile phone coverage and the growing rate increases by 49 percent annually. In Tanzania the penetration is approximately 80 percent and those using mobile internet services are 40 percent of them (Aker and Mbiti, 2011; Tanzania Communication Regulatory Authority, 2017).

The proposed solution as shown in Figure 2, expects to work by providing two options in pesticides authenticity verification requests, as described below.

First option is to capture image of the part of the product which contains batch number and send it to the system. The image is received by the python flask application and being processed and texts are extracted, then from the extracted text batch number is sent to the MySQL server for matching.

Second option in authenticity request is that the batch number is entered and sent to the system, then to the MySQL database for matching.

For both options (image and text), just in case the match is found, the system replies the found product information, like; batch number, product registration number, name of the product, manufacturer and registrant of the product, production and expiry dates of the particular product. Aiming for the requester to match the replied product information with the information found in the actual product to be bought. In case the match isn't found in the MySQL database then the system replies the alert message for user not to purchase the product as it is not authentic.

Similarly for both options (image and text), mobile application captures the longitude and latitude of the requester in the background. So just in case the match isn't found in the database they are used to create a map with red markers (as sample shown in Figure 3). This map would help the regulatory authority in identifying threat areas and act accordingly. 
On the other hand the mobile application will have a complaint reporting service to users. Where information like; product image, batch number, registration number, source of product and harm which the user has encountered are to be filled and sent to the server for the regulatory authority to work immediately on them.

The MySQL database expects to contain updated information about pesticides products. The information is to be managed by the inspectors at the regulatory authority. As soon as the pesticide product has been undergone laboratory analysis and found that has the expected quality, then the product information is to be updated to be accessed by the pesticides users through mobile application. Also the regulatory authority inspectors will be able to manage details of the authenticity requests and the reported complaints.

\section{CONCLUSION}

As far as this study is concerned it is evident from literature and the reported findings, that there is a need for an ICT based solution for pesticides authenticity verification. Through the proposed solution pesticides customers will have a chance to check authenticity of the pesticides product and report complaints for products which haven't worked as expected.

It is clear that this study will serve as a link between other pesticides stakeholders and the regulatory authority and hence brings a solid foundation for pesticides authenticity in Tanzanian market.

In future this study can be extended to accommodate USSD codes so that even pesticides users with featured phones would be able to utilize the authenticity check service by entering direct the batch number to get reply on the product status through SMS (Short Message Service), on whether the product is authentic or not.

\section{REFERENCES}

Aker, J. C. and Mbiti, I. M. (2011). Mobile Phones and Economic Development in Africa, $24(3), 207-232$. https://doi.org/10.2139/ssrn.1693963

Ashour, M., Billings, L., Gilligan, D. O., Karachiwalla, N., Billings, L. and Gilligan, D. O. (2015). Evaluation of the Impact of e-verification on Counterfeit Agricultural Inputs and Technology Adoption in Uganda. International Food Policy Research Institute. Washington, DC 20006 USA.

Carnoy, M. (2005). ICT in Education: Possibilities and Challenges. Universitat Oberta de Catalunya.

Denscombe, M. (2014). The Good Research Guid: For Small-scale Social Research Projects (5th Editio). UK: Mc Graw Hill Education.

Fei, W.-C. (2014). Development of Regulatory Information System on Pesticide Products. In Food and Fertilizer Technology Center (pp. 110-122).

Fishel, F. M. (2009). The Global Increase in Counterfeit Pesticides 1. Agronomy Department, UF/IFAS Extension. Florida, 32611.

Hartung, C., Anokwa, Y., Brunette, W., Lerer, A., Tseng, C. and Borriello, G. (2010). Open Data Kit: Tools to Build Information Services for Developing Regions. In Proceedings of the International Conference on Information and Communication Technologies and Development (pp. 1-11). https:/ / doi.org/10.1145/2369220.2369236

Idowu, B., Ogunbodede, E. and Idowu, B. (2003). InformationandCommunicationTechnologyinNigeria TheHelathSectorExperience. Journal of Information Technology Impact, 3(2), 69-76.

Isah, H. (2012). Information and Communication Technology in Combating Counterfeit Drugs Keywords. Department of Computing, School of Informatics, Computing and Media (SCIM) University of Bradford, Richmond Road BD7 1DP, Bradford UK. University of Bradford, UK.

Lahr, J., Buij, R., Katagira, F. and Valk, H. Van Der. (2016). Pesticides in the Southern Agricultural Growth Corridor of Tanzania (SAGCOT). Wageningen, The Netherlands.

Liao, S. and Ma, Y. (2009). Conceptualizing Consumer Need for Product Authenticity. International Journal of Business and Information, 4(1), 89-114.

Lwoga, E. T., Stilwell, C. and Ngulube, P. (2010). Access and use of agricultural information and knowledge in Tanzania. Dar es Salaam, Tanzania.

Meng, X. (2013). Scalable Simple Random Sampling and Stratified Sampling. Proceedings of the 30th International Conference on Machine Learning, 28(1), 1-9.

Ngowi, A. V. (2002). Health Impact of Exposure to Pesticides in Agriculture in Tanzania. University of Tampere.

Shao, D. and Edward, S. (2014). Combating Fake Agro-Inputs Products in Tanzania using Mobile Phones. International Journal of Computer Applications, 97(17), 1-5. https:/ / doi.org/10.5120/17264-7636

Singh, Smita and Panchal, K. (2015). Study on Sub-Standard/Counterfeit Pesticides in India. New Delhi.

Syngenta. (2011). Mobile Applications in Agriculture. Syngenta Foundation, Basel, Switzerland. Basel, Switzerland. 
Tanzania Communication Regulatory Authority. (2017). April- June 2017 Quarter. TCRA, reports (Vol. 2). Dar es Salaam, Tanzania.

Tashakkori, A. and Teddle, C. (1998). Mixed Methodology: Combining Qualitative and Quantitative Approaches. (C. D. Laughton, Ed.). SAGE Publications.

Tashakkori, A. and Teddlie, C. (2010). SAGE Handbook of Mixed Methods in Social \& Behavioral Research (Second Ed). Thousand Oaks, California: SAGE Publications, Inc. https:// doi.org/10.4135/9781506335193

The United Republic of Tanzania. (2012). National Sample Census of Agriulture 2007/2008 Regional Report: Arusha Region Volume Vb. National Bureau of Statistics.

Tinio, V. L. (2002). ICT in Education. New York.

Tropical Pesticides Research Institute. The Pesticides Control Regulations (1984). United Republic of Tanzania.

U.S. (NIEHS). (2016). Pesticides. Available at: https://www.niehs.nih.gov/health/topics/agents/pesticides/ (Accessed 27 March 2017)

Vassiliadou, S., Mpoutakidis, D. and Karikas, M. (2011). Application of Relational Database in Listing Pesticides used in Greece according to their Hazards in Human Health and the Environment. In International Conference on Information and Communication Technologies for Sustainable Agri-production and Environment (pp. 463-471). Greece.

Vitanova, V., Atanasova-Pachemska, T., Iliev, D. and Pachemska, S. (2015). ScienceDirect Factors Affecting the Development of ICT Competencies of Teachers in Primary Schools. Procedia - Social and Behavioral Sciences, 191, 1087-1094. https://doi.org/10.1016/j.sbspro.2015.04.344

Yáñez, L., Ortiz, D., Calderón, J., Batres, L., Carrizales, L., Mejía, J., ... Díaz-barriga, F. (2002). Overview of Human Health and Chemical Mixtures: Problems Facing Developing Countries. Environmental Health Perspectives, 110 (December 2001), 901-909. https:// doi.org/10.1289/ehp.110-1241270 